\title{
Boris Schnaiderman:
}

\section{questões de tradução \\ nas páginas de jornal}

BRUNO BARRETTO GOMIDE

A HISTÓRIA da recepção da literatura russa no Brasil remonta a fins do século XIX e possui muitos personagens. Não há dúvidas, contudo, de que o começo da atividade ensaística e tradutória de Boris Schnaiderman constitui o ponto nevrálgico no nosso contato com a multifacetada experiência russa.

Estender-se na biografia de Boris Schnaiderman é desnecessário, posto que ele é um dos intelectuais mais conhecidos do país. É uma vida que toca os pontos fortes da história do século XX. Poderíamos apenas mencionar o seu nascimento, em 1917, entre as revoluções de fevereiro e de outubro; a infância em uma Odessa fervilhante, na qual testemunha, em episódio famoso, a filmagem da cena-chave de O encouraçado Potiômkin; a experiência da emigração, em 1925; os percalços da vida de judeu russo durante a ditadura do Estado Novo; a participação na campanha da FEB, como sargento de artilharia - para mencionar apenas o período anterior ao do seu efetivo trabalho de comentador dos temas russos, começado a partir da segunda metade da década de 1950.

Mas é uma trajetória composta também por tons "menores", atividades que margeiam o anonimato: o trabalho de professor de agronomia em Barbacena, a redação de verbetes para enciclopédia, as primeiras traduções com pseudônimo. Desde a chegada ao Brasil, o processo árduo de conquista da própria voz, em meio às vivências russas e brasileiras, processo cujas angústias Boris Schnaiderman sempre destacou em entrevistas.

A hesitação entre o aparecer e o esconder-se está presente na escolha do pseudônimo com que ele traduziu suas primeiras obras para a editora carioca Vecchi, em meados da década de 1940. O Boris Solomônov que figura como tradutor de Os irmãos Karamázov mantém o nome inicial do tradutor e transforma o seu patronímico (Solomônovitch) em sobrenome. Não é, portanto, um pseudônimo "total". Deriva da ambiguidade de um jovem tradutor que oscila entre gestos de ousadia - a tradução de um dos romances mais importantes de todos os tempos - e de introversão, cônscio de que o trabalho intelectual deve ser sempre rigoroso e das dificuldades colossais envolvidas na empreitada. A obra de Boris Schnaiderman estará sempre marcada por uma tensão desse tipo, entre um polo arrojado, explosivo, e outro mais contido, minucioso, implosivo. Talvez os títulos de vários de seus livros, que em geral formam oposições semân- 
ticas, espelhem de algum modo essa variação, lastreada no modo como o autor encara o universo da literatura: turbilhão/semente, guerra/surdina, poesia/prosa, clamor/silêncio, mito/escombros, desmedido/tradução.

Esses livros com títulos sonoros são uma pequena fração da contribuição inestimável que Boris Schnaiderman vem dando à cultura brasileira. De igual importância é a sua obra dispersa, cerca de 350 textos publicados na imprensa, quase sem interrupção, desde fins de 1956 até hoje. Proponho, a seguir, um breve comentário sobre alguns temas-chave que aparecem nesses textos, com destaque para o papel da reflexão sobre a tradução.

Fatores contextuais criaram um ambiente propício para a discussão de temas russos e soviéticos e contribuíram para o início da atividade literária de Boris Schnaiderman, com traduções e artigos nas páginas de jornais, especialmente na coluna "Letras Russas" do Suplemento Literário de O Estado de S. Paulo. Seu primeiro artigo, uma resenha do livro do escritor turco Nazim Hikmet, Mas, existiu Ivan Ivánovitch?, foi publicado em dezembro de 1956, encerrando um ano aberto pelo discurso "secreto" de Khruschióv, em fevereiro, e ainda sob a marca do levante húngaro, esmagado pela invasão soviética no começo de novembro. As dezenas de artigos publicados por Boris Schnaiderman nos anos seguintes refletem o amplo interesse internacional suscitado pelos "feitos" sovié-ticos - em certo sentido, são tributários do Spútnik, satélite cujos sinais enviados para a terra tiveram o efeito inaudito de criar cursos de língua russa mundo afora (e de reforçar alguns já existentes, como é o caso de várias universidades estadunidenses, que se dotaram de financiamentos polpudos e robustas bibliotecas especializadas). Depois da revolução cubana, em 1959, a América Latina se tornou uma prioridade para a União Soviética. Houve edições de autores latino-americanos, alguns já velhos conhecidos do bloco socialista, outros novos para os russos, como Machado de Assis. O estudo profissional da cultura brasileira fortaleceu-se na União Soviética; lá e cá foram criadas missões culturais, festivais de dança e cinema, possibilidades de viagens de pesquisa.

Ajudou o fato de que, entre 1956 e 1964, quando Boris Schnaiderman publica grande número de traduções e de artigos, lança seu primeiro livro (Guerra em surdina) e participa da criação do curso de russo da USP, o Brasil vivia um raro intervalo entre regimes autoritários, quando as tendências anticomunistas, nunca extintas, encontravam-se ao menos esmaecidas. Nos anos imediatamente seguintes ao golpe militar, o ritmo das publicações de Boris Schnaiderman em jornal diminui consideravelmente. Após um artigo sobre os contos de Ricardo Ramos ("Caminhos da rua desfeita", O Estado de S. Paulo), publicado no dia 21 de março (no mesmo dia da nota sobre E. Etkind adiante mencionada), o texto seguinte só sairá em jornal um ano depois, em um intervalo inédito até então no ritmo de publicações. Entre 1956 e 1964, são 105 artigos; no mesmo período de tempo, de 1964 a 1971, apenas 35. A carga de aulas intensa que o professor Boris tinha na USP certamente foi responsável pela redução no ritmo do seu 
jornalismo cultural, mas é bastante plausível supor que as injunções políticas tiveram papel decisivo.

Em meio a essa centena de textos iniciais, podemos perceber temas e linhas de força que atravessarão a obra de Boris Schnaiderman até os dias de hoje. Esses textos podem ser iniciais, mas não são iniciantes, publicados como foram por um autor que já entrava na casa dos quarenta e estreava nas letras, com a própria assinatura, relativamente maduro. O escopo varia da resenha breve e da nota informativa a verdadeiros ensaios, estudos de alta qualidade que poderiam figurar em qualquer antologia de crítica literária sobre temas russos produzida no mundo.

O conjunto desenha certas preferências que terão continuidade na obra de Boris Schnaiderman. Tchékhov, Górki, Tolstói e Dostoiévski serão sempre autores muito comentados. Gógol e Turguêniev ocuparão pouco espaço. Artigos importantes sobre literatura brasileira e teoria literária aparecem com frequência. E, sobretudo, a literatura soviética surge com uma profusão de nomes desconhecidos para o leitor brasileiro: Grin, Panova, Katáiev, Paustóvski, Oliécha, Fiédin, Khliébnikov, Tzvietáieva, Mandelstam. Mesmo os autores já conhecidos por aqui ressurgiam, tratados agora em um nível muito mais profissional. $\mathrm{O}$ artigo de 1959 sobre o autor de A cavalaria Vermelha ("A volta de Isaac Bábel") exemplifica a diferença abissal existente entre essa nova produção e a média do ensaísmo russista no Brasil. O mesmo valeria para Ehrenburg, Maiakóvski e tantos outros. Boris Schnaiderman depura os clichês e a retórica grandiloquente que tradicionalmente colava-se à literatura russa. O resultado mescla o texto enxuto e objetivo ao tom caloroso advindo do comprometimento ético e da vivência pessoal com os temas tratados. O valor desse trabalho, na escolha dos autores e no modo como eles são estudados, ganha ainda mais vulto quando nos lembramos da dificuldade, à época, para a obtenção de materiais russos no exterior.

Há quatro constantes nesses textos iniciais, mantidas na obra subsequente de Boris Schnaiderman: 1) o elogio ao fator moderno na arte e concomitante crítica aos aspectos cediços e passadistas; 2 ) a literatura russa deve ser primeiramente encarada pelo seu caráter estético (sem que isso enseje desconsideração de implicações históricas, biográficas e existenciais). O título dado a um livro traduzido por Boris Schnaiderman em 1967, reunindo estudos do crítico soviético Leonid Grossman, Dostoiénski artista, resume bem esse espírito; 3) a cultura soviética não é um monolito. É muito mais rica e variada do que se julgava na época, e não se reduz à vulgata promovida pelo realismo socialista. Boris Schnaiderman, aliás, sempre observou, em uma posição ousada, que esse modelo literário não era necessariamente ruim em si: o problema maior era a sua transformação em ortodoxia. Em seus melhores momentos, portanto, a nova literatura soviética nada deve à grande literatura russa do século XIX; 4) a tradução literária é sempre um trabalho que requer um equilíbrio complexo entre rigor e arrojo. 
Uma parcela substancial dos primeiros artigos jornalísticos de Boris Schnaiderman trata da tradução. São textos escritos exclusivamente sobre o tema, ou que o comentam de forma lateral.

Uma tônica é a crítica feita às traduções de literatura russa existentes no Brasil. Em "Traduções do russo" (O Estado de S. Paulo, 7.2.1959), Boris Schnaiderman elogia a "atividade criminosa" de muitos tradutores do passado, em vários países, mas sugere que o futuro é promissor:

É preciso insistir, no entanto: no presente, há condições, no Brasil, para a apresentação de boas traduções de autores russos. Além da maior facilidade em se obterem ótimas edições em diferentes línguas, têm aparecido algumas traduções diretas que parecem realmente auspiciosas. Tivemos oportunidade de comparar com o original a tradução do conto "Angústia", de Tchékhov, (Mar de Histórias, JO, 1958, $3^{\circ}$ vol.), feita diretamente do original, por Paulo Rónai e Aurélio Buarque de Holanda, e ficamos agradavelmente surpreendidos com a capacidade dos tradutores em transmitir o espírito da obra, a atmosfera tipicamente tchekhoviana do conto. Pareceu-nos igualmente muito boa e fiel a tradução de Tatiana Belinky de outro conto de Tchékhov ("A mulher do farmacêutico"), incluído em Maravilhas do conto universal, da Ed. Cultrix, 1958. Em suma, se há condições para o aparecimento de boas traduções de autores russos, é preciso, contudo, que os editores sejam muito cautelosos. Referindo-se às liberdades que muitos tradutores franceses tomavam com a obra de Tolstoi, Romain Rolland escreveu, no prefácio à segunda edição de seu estudo sobre o escritor: "é preciso que Tolstoi seja bem grande para ainda parecê-lo, depois de todos esses ultrajes". O mesmo se poderia dizer da literatura russa em geral, tão difundida no mundo, mas cuja face autêntica é, muitas vezes, tão difícil de perceber, através das deformações ridículas de que foi vítima com tamanha freqüência.

Boris Schnaiderman, com sua modéstia habitual, não mencionou as próprias traduções de Tchékhov, em curso de publicação, que evidentemente estavam entre os pontos mais altos do processo descrito.

Observações sobre traduções existentes também aparecerão na resenha de uma obra de I. S. Búnin (O Estado de S. Paulo, 21.6.1958), em que Schnaiderman elogia versões do conto "O cavalheiro de $S$. Francisco" existentes em antologias dos anos 1940 e 1950. "Tchékhov novelista" (O Estado de S. Paulo, 7.11.1959) contém um breve panorama das novelas de Tchékhov disponíveis em português e uma observação sobre a pouca divulgação que elas tiveram, do que decorreria a necessidade de preparação de "uma edição metódica de conjunto" (que o próprio Boris Schnaiderman iria providenciar tempos depois).

Há diversos comentários sobre as dificuldades específicas da tradução poé-tica. Em um artigo sobre uma nova edição russa de um clássico da literatura infantil, "O cavalinho corcunda", de Piotr Ierchóv, um texto de 1834 elogiado por Púchkin, Boris Schnaiderman sugere que ele

bem merece uma tradução para o português. É verdade que a tradução poética apresenta sérias dificuldades. Grande parte do sabor local perder-se-ia em 


\section{Traduções do russo}

$A^{\text {pesar das inumeras edições }}$ 1 tem no Ocidente, a literatura russa é, sem duvida, uma das mais sacrificadas por traducões criminosas. Elsa Triolet escreveu, no preambulo de seu L'Histoire d'Antoine Tchekhov: "Parler d'un auteur étranger, dont le nom est eélébre, mais l'oeuvre mal connue d'aprés des traductions souvent imparfaites, est comme parler couleurs á un aveugle de naissance". Realmente, nada há de exagerado nessa
afirmação.

No caso da's edições brasileiras, a situação foi agravada pe 10 uso-generalizado do francês do espanhol como inguas intermediarias, geralmente sem um controle eficaz das edições ut lizadas para tal fim. Realmente, devido a certas dificuldades do meio, não se pode esperar que os editores apresentem sempre traduções diretas. 0 importante, agora, é evitar certos erros, bem graves, cometidos ás veze em boa-fé, simplesmente com uso de algumas edicōes france uso de algumas edicoes france sas ou espanholas, precedidas, mesmo, de uma fama, de serie-

$\mathrm{Na}$ seleçāo das traduções de classicos, o maior cuidado deve consistir em evitar, com rara exceçōes, as mais antigas, devido a certas particularidades da grande difusão da literatura rus sa no Ocidente, a partir de fins do seculo passado Depois que Velchior de Vogué apregoou ceschior grandeza dos escritores russos. os . editores franceses interessaram-se particularmente por eles, e o publico francês passou tam bem a procurar com avide aquelas obras. Todavia, os edito res logo se depararam com um serio problema. Poderia o grande publico, tão interessado, na epoca, pelos "misterios da alma eslava", receber de chofre romances quilometricos, como a

\section{BORIS SCHNAIDERMAN}

mais de trezentas paginas, em lugar das mil e tantas do origi. nal. E foi sobre esta edição que se basearam alguns editores portugueses, espanhois, brasileiros outros, para apresentar aos resoutros, para apresentar aos respectivos publicos aquele roman ce de Dostoievski, mas geralmente sem a honesta advertencia do editor francês, no sentido de que se tratava de uma adaptação. Traduções desta continuaram sair em diversos paises, até há poucos anos, mesmo depois de aparecerem outras baseadas no texto integral, como a incluida na edicão espanhola das nas obras Plar, 1935), da Aguilar, 1935), em traduão de $\mathrm{R}$. Cansino Assens, que realizou trabalho de alto nivel, ape sar de algumas liberdades lige ras em relação ao original.

Para se perceber a que ponto os editores de alguns paise ocidentais temiam a tradução fiel de muitos textos russos, bas ta lembrar que, passados quarenta anos da morte de Dostoiêvski, Gide apresentava como um fato extremamente auspicioso fato extremamente auspicioso enta proximo Irmáos Karamazov, rancesa integral.

- Outras obras fundamentais da literatura russa foram igualmen te prejudicadas em sua divulgação no Ocidente, devido á ação criminosa de alguns editore franceses. Serge Persky exerceu, por exemplo, uma intensa atividade como tradutor de obras russas, além de publicar diversos estudos. Suas traducões de Górki são frequentemente cón panhadas da observação "traduit daprés le manuscrit", mas, na traduça da famosa trilogia au minar alguns dos trechos mais de ficção đe Dostoîêvski para o inglês, por Constance Garnett, e que se tornaram classicas. A atividade do tradutor inglês Aylmer vidade do tradutor inge An Louise Maude, está intimamente relacionada com a difusão da obra lacionada com a difusão da obra de Tolstói no Ocidente. 0 tradutor mantinha correspondencia com o escritor, e este lhe manifestou, em mais de uma oportunidade, sua aprovação pelo trabalho realizado. A honestidade profissional de Maude permitiu até reconstituir aproximadamente rom te o texto original de algumas passagens da obra de Tolstól. Assim, comparando o texto rus so impresso em Sebastopol com sua propria tradução, Maude estranhou, em carta ao escritor o aparecimento de frases, que foram acrescentadas por um redator da censura. Este sacrificara implacavelmente a obra e, visto que Tolstói não conservara manuscrito, o melhor meio para uma reconstituicão do texto pasuma reconsticus so, anos mais tarde,

Houve também edições alemãs Houve tambem ediçoes alemás
tão superiores, geralmente, ás francesas da epoca, que Gide serviu-se delas para conhecer melhor Dostoiêviski.

Atualmente, a situação mudou bastante. Além de serem acessiveis' otimas traduções do russo em alemão, italiano, espanhol, inglês etc., os proprios editores glês etc., os proprios editores franceses não se arriscam mais a deturpações como as de Persky e há textos excelentes ế. Mesmo assim, porém continua grande a tentação de adaptar um pouco o original 'torná-lo mais facil ao leitor, não por meio de notas explicativas, mas pela alteracão e pela traducão muito livre Dostoiêvski continua sendo uma tos sendo uma grande vitim dos tradutores. Seu estilo náo culdades consideraveis de tra- de Niétotchka Niezvánova, por Henri de Mongault e Lucie Désormonts (Bibliothéque de la Pléiade, 1952). Assim, no trecho em que Niétotchka acompanha o padrasto pelas ruas de Petersburgo, após a morte da mãe, e em que ele desce para junto de um canal, sentando-se sobre a ultima baliza, o texto original diz: "A dois passos de nós, havia um vão". Mas, na tradução (pag. 1.116), ficou: "A deux pas de nous, l'eau tourbillonait". No trecho om impresão de Niétotansmite a morte do morte do padrasto, está. "Ele morrel, porque semelhante morte era algo indispensavel, uma consequencia de toda a sua vida”. E na tradução francesa (pag. 1.118): "Mort! Pareille fin était la conséquence naturelle, obligatoire de la vie qu'il avait menée". Ora, o ponto de exclàmação acrescenta á frase um patético incompativel com a inten cão do autor maunele trecho.

E' preciso insistir, no entanto: no presente, há condições, no Brasil, para a apresentação de boas traduções de autores russos. Além da maior facilidade em se obterem otimas edições em diferentes linguas, têm aparecido algumas traduçōes diretas, que parecem realmente auspicioses. parecos rive rar com original a traduçao do conto "Angustia" de Tchekhoy (Mar de Historlas, 3.0 vol, Editora José Olimpio, 1958), feita diretamente do original, por Paulo Rónai e Aurélio Buarque de Holanda, e ficamos agradavelmente surpreendidos com a capacidade dos tradutores em transmitir o espirito da obra, a atmosfera tipicamente tchekho viana do conto Pareceu-nos vina do conto. Pareceu-nos trialmente muto boa tradução de Tatiana Belinky de outro conto de Tchekhov (A Mulher do Farmaceutico"), inUniversal, da Editora Cultrix, 1958.

Em suma, se há condiçōes para

Fac-símile de "Traduções do russo", de Boris Schnaiderman (O Estado de S. Paulo, 7.2.1959).

qualquer tradução. E para uma verdadeira transposição poética seria preciso que um Manuel Bandeira, por exemplo, conhecesse bem o russo e se decidisse à empresa. (Para Todos, $1^{\text {a }}$ quinzena de novembro de 1957)

Pode-se ver que Boris Schnaiderman já está apontando para o processo de parceria que, no começo da década seguinte, vai se desenhar entre ele e os irmãos Haroldo e Augusto de Campos. Os artigos de jornal trazem vários frutos dessa associação, como em "Maiakóvski reeditado na Rússia" ( $O$ Estado de S. Paulo, 8.4.1961), "Um paradoxo de Maiakóvski" (O Estado de S. Paulo, 6.5.1961), "Carta a Tatiana Iacovleva" (O Estado de S. Paulo, 29.9.1962) e "Dois temas russos" ( O Estado de S. Paulo, 16.11.1963), textos que contêm não apenas problemas teóricos relativos à tradução, mas também versos do poeta russo, finalmente disponível em português fora da condição verborrágica em que habitualmente era alocado. $\mathrm{O}$ tema das particularidades da tradução poética percorre também um dos seus mais fascinantes estudos comparativos, "Púchkin, tradutor de Gonzaga" ( O Estado de S. Paulo, 16.6.1962). 
Em alguns artigos, a voz de outros autores serve para comunicar ideias do próprio Boris Schnaiderman. A tradução do artigo "Arte moderna na União Soviética" (O Estado de S. Paulo, 3.9.1961), fragmento da autobiografia Gente, anos, a vida, do escritor soviético Iliá Ehrenburg (que Boris Schnaiderman iria em parte traduzir), fala da incrível atuação da vanguarda no primeiro contexto soviético e de sua dispersão em tempos subsequentes. Na mesma linha, "Tradução e estilo" ( $O$ Estado de S. Paulo, 21.3.1964) é uma nota sobre o livro Teoria e crítica da tradução, editado pela Universidade de Leningrado, em que o grande crítico e tradutor Efim Etkind

ataca as traduções em que se procura atingir um estilo médio, isto é, enxuto, correto, arrumado, mas sem maior arrojo, na transposição das peculiaridades estilísticas de um autor [...] Etkind afirma que, para superar essas deficiências, é preciso difundir melhor as modernas concepções teóricas sobre a tradução literária, baseadas na estilística comparada.

"Arrojo" é a palavra mais presente nos ensaios de Boris Schnaiderman sobre a tradução, desde fins dos anos 1950 até o recente livro Tradução: ato desmedido, e reverberada no meio-tempo em inúmeras entrevistas. Os artigos daqueles anos iniciais permitem mapear um movimento geral no sentido da audácia, da fuga da literalidade, da exigência de inclusão de princípios modernos e vanguardistas. Esses princípios são fios condutores que ligam as diversas esferas da atividade do autor: a orientação presente nos artigos corria em paralelo à redação da primeira e única experiência ficcional de Boris Schnaiderman, o romance Guerra em surdina, lançado em 1964, mas cujo projeto remontava à época da guerra. Um modo de se interpretar esse romance é vê-lo como uma tentativa de se reintroduzir o experimentalismo moderno, mediante uma complexa mistura de gêneros, em um tema tão malbaratado quanto o da literatura sobre a Segunda Guerra Mundial, abordada, tanto no caso russo-soviético quanto no brasileiro, por propostas herdadas de esquemas realistas-naturalistas requentados do século XIX.

Nesse sentido, o contato com Haroldo e Augusto de Campos entende-se, de forma mais apropriada, como uma afinidade eletiva. Ele certamente ajudou a radicalizar o modo como Boris Schnaiderman enxergava os métodos do tradutor. Porém, o elogio ao aspecto dinâmico e radical do texto literário já está embutido em seus comentários sobre a ficção breve de Oliécha, Katáiev, Bábel e tantos outros, feitos desde as primeiras linhas dos primeiros artigos publicados em jornal, nos quais Schnaiderman lamenta a substituição da ousadia por procedimentos mais tradicionais, derivados ora de transformações internas à própria vida e obra daqueles autores, ora resultado de pressões exteriores. A centena de textos iniciais escritos por Boris Schnaiderman na virada das duas décadas, ao equacionar o elemento moderno na literatura com o moderno no processo tradutório, já seria suficiente para colocar o seu autor no rol dos grandes críticos brasileiros, dos renovadores do pensamento sobre a tradução e dos grandes eslavistas do século XX. 
RESUMO - Proponho neste artigo indicar a importância dos artigos de jornal publicados por Boris Schnaiderman entre 1956 e 1964, aproximadamente uma centena de textos nos quais as questões de tradução literária ocupam lugar-chave.

PALAVRAS-CHAVE: Tradutor, Tradução do russo, O Estado de S. Paulo, Boris Schnaiderman.

ABSTRACT - In this paper I propose to point out the importance of newspaper articles published by Boris Schnaiderman from 1956 to 1964, comprising approximately one hundred texts in which literary translation issues are pivotal.

KEYWORDS: Translator, Translation from Russian, O Estado de S. Paulo newspaper, Boris Schnaiderman.

Bruno Barretto Gomide é professor de Literatura Russa na Universidade de São Paulo. Autor de, entre outros, Da estepe à caatinga: o romance russo no Brasil (1887-1936) (Edusp, 2011); Nova antologia do conto russo (Ed. 34, 2011); e Antologia do pensamento crítico russo (Ed. 34, no prelo). @-bgomide@hotmail.com

Recebido em 22.8.2012 e aceito em 27.8.2012. 
